\title{
Syphilis Testing as a Proxy Marker for a Subgroup of Men Who Have Sex With Men With a Central Role in HIV-1 Transmission in Guangzhou, China
}

\begin{abstract}
Liping Huang ${ }^{1 \dagger}$, Hao $\mathrm{Wu}^{2 \dagger}$, Huanchang Yan ${ }^{1 \dagger}$, Yuanhao Liang ${ }^{1}$, Qingmei $\mathrm{Li}^{2}$, Jingwei Shui ${ }^{1}$, Zhigang $\mathrm{Han}^{2,3 *}$ and Shixing Tang ${ }^{1,4 *}$

1 Department of Epidemiology, School of Public Health, Southern Medical University, Guangzhou, China, ${ }^{2}$ Department of AIDS Control and Prevention, Guangzhou Center for Disease Control and Prevention, Guangzhou, China, ${ }^{3}$ Institute of Public Health, Guangzhou Medical University, Guangzhou, China, ${ }^{4}$ Wenzhou Institute, University of Chinese Academy of Sciences, Wenzhou, China
\end{abstract}

OPEN ACCESS

Edited by:

Marc Jean Struelens,

Université libre de Bruxelles, Belgium

Reviewed by:

Aruni Wilson,

Loma Linda University, United States

Zhongqing Xu,

Shanghai Jiao Tong University School

of Medicine, China

*Correspondence:

Shixing Tang

tamgshixing@smu.edu.cn

Zhigang Han

zhiganghan616@163.com

tThese authors have contributed equally to this work and share first

authorship

Specialty section:

This article was submitted to Infectious Diseases - Surveillance,

Prevention and Treatment,

a section of the journal

Frontiers in Medicine

Received: 01 February 2021 Accepted: 26 May 2021

Published: 07 July 2021

Citation:

Huang L, Wu H, Yan H, Liang Y, Li Q,

Shui J, Han Z and Tang S (2021)

Syphilis Testing as a Proxy Marker for

a Subgroup of Men Who Have Sex With Men With a Central Role in HIV-1

Transmission in Guangzhou, China.

Front. Med. 8:662689.

doi: 10.3389/fmed.2021.662689
Objectives: The objectives of this study were to distinguish the role of men who have sex with men (MSM) with or without syphilis testing in HIV-1 transmission and to provide molecular evidence of syphilis testing as a proxy marker for identifying the subgroup of MSM.

Methods: HIV-1 transmission clusters were constructed by HIV-TRACE and Cluster Picker using HIV-1 pol sequences from 729 newly diagnosed HIV-infected MSM from 2008 to 2012 in Guangzhou, China. The role of MSM in HIV-1 transmission networks was determined by a node influence measurement and centrality analysis. The association between syphilis testing and factors related to HIV-1 transmission and antiretroviral treatment (ART) were analyzed by the Cox regression model.

Results: Among HIV-infected MSM, 56.7\% did not test for syphilis at the time of HIV-1 diagnosis. MSM without syphilis testing was a specific subgroup of MSM with a larger closeness centrality and clustering coefficient than the recipients of syphilis testing $(P<$ 0.001), indicating their central position in the HIV-1 transmission networks. The median degree and radiality within HIV-1 transmission networks as well as the median K-shell scores were also greater for MSM without syphilis testing $(P<0.001)$, suggesting their relatively greater contribution in transmitting HIV-1 than the receipts of syphilis testing. MSM with syphilis testing usually did not disclose their occupation or were more likely to be unemployed or to take non-skilled jobs, to have a history of sexually transmitted infections (STIS), and to be AIDS patients when diagnosed with HIV-1 infection $(P<$ 0.05). Multivariable Cox regression analysis indicated that syphilis testing per se did not promote the engagement of ART $(P=0.233)$ or affect the speed of $\mathrm{CD} 4^{+} \mathrm{T}$ cell count recovery after treatment $(P=0.256)$.

Conclusions: Our study identifies syphilis testing as a proxy marker of a specific subgroup of HIV-infected MSM who refuse syphilis testing during HIV-1 diagnosis with an important role in HIV-1 transmission. Specific prevention and intervention targeting MSM without syphilis testing during HIV-1 care are urgently needed.

Keywords: syphilis, HIV-1, transmission network, screening, men who have sex with men 


\section{INTRODUCTION}

Over the past decades, syphilis has continued to spread globally, and disproportionately affects men who have sex with men (MSM) who are often co-infected with human immunodeficiency virus type one (HIV-1) (1-3). In light of the fact that syphilis and HIV-1 infection could facilitate the acquisition and transmission of each other, and even alter mutual disease progress (4-6), integrating syphilis testing into HIV-1 care has been recommended and promoted to curb the dual epidemic of syphilis and HIV-1 (7-9).

In China, despite the launch of a nationwide 10-year syphilis control plan in 2010 to promote the integration of HIV-1 and syphilis testing in the clinics of sexually transmitted infections (STIs) (10), there has been a continuous increase of syphilis cases and HIV-1/syphilis co-infections among MSM over the past decade $(3,11-13)$, due to low uptake of syphilis testing among HIV-infected MSM and other high-risk individuals in China $(10,13,14)$. Furthermore, the current syphilis screening service might not fully cover all the risk groups. Hall et al. (13) have reported that MSM who did not engage in sex work were less likely to be tested for either HIV or syphilis. It is thus important to precisely determine the subgroup of MSM and to understand their difference in HIV-1 transmission (15). However, few studies have been published in China to investigate the role of MSM with or without syphilis testing in the control of HIV-1 epidemics (15), due to the lack of accurate and reliable information for MSM (16). Now, transmission network analysis using HIV-1 viral sequences has been revealed to be a valuable method to restore the social network of HIV-infected individuals in particular when epidemiological information, such as sexual behaviors, are not available or are inaccurate. The information obtained from HIV1 transmission network topological structures may serve as a proxy for individuals with enhanced HIV-1 transmission risk $(17,18)$. For example, Ragonnet-Cronin et al. (19) adapted timeresolved phylogenetic analysis and HIV-1 transmission network analysis to identify $18.6 \%$ of all clustered heterosexual men as non-disclosed MSM in the UK. Based on HIV-1 transmission network analysis, we also found that non-disclosed MSM was a specific group and played a central role in HIV-1 transmission in China (20).

Therefore, in the current study, we adapted transmission network analysis to uncover the HIV-1 transmission risk among MSM with or without syphilis testing. We aimed to characterize the subgroup of MSM who refuse to test for syphilis and to provide molecular evidence of their important role in enhancing HIV-1 transmission in China.

\section{MATERIALS AND METHODS}

\section{Study Setting, Participants, and HIV-1 Sequences}

Guangzhou is an international metropolis in the southern part of China, where the HIV-1 epidemic in MSM has been clustered for decades (21). The Center for Diseases Prevention and Control (CDC) is in charge of all HIV-1 cases in Guangzhou, including the diagnosis and confirmation of HIV-1 infection, CD4 cell measurement, and syphilis testing, etc. Eligibility criteria, recruitment, and measurement procedures for HIV-infected MSM have previously been described (22). Free consulting and testing for syphilis were available for all MSM at the time of HIV1 testing or diagnosis, but they decided whether to take syphilis screening or not. Follow-up examinations were done every 36 months from June 2008 to February 2015. Demographic and laboratory testing data were collected from the medical charts of Guangzhou CDC. Blood samples were collected from 982 newly diagnosed and antiretroviral therapy (ART)-naïve HIV-1infected MSM in Guangzhou CDC between January 2008 and December 2012. HIV-1 pol sequences (equal to the fragment of nucleotide 2,253-3,821 for the HIV-1 HXB2 strain) were successfully amplified by reverse transcription polymerase chain reaction (RT-PCR) and sequenced. The sequence data have been deposited in GenBank with the accession numbers listed in the Supplementary Material. Finally, a total of 729 ( $74.2 \%, 729 / 982)$ HIV-infected MSM were included in our study. The flow chart of the study is presented in Supplementary Figure 1. This study was approved by the Institutional Review Board of Guangzhou CDC (No. 2017030). Written informed consent was obtained from all the participants.

\section{Phylogenetic Analysis}

HIV-1 pol sequences were aligned using the reference sequences of HIV-1 group M and the circulating recombinant forms (CRFs) obtained from the Los Alamos HIV-1 database (http://www.hiv. lanl.gov). HIV-1 genotypes were determined by the phylogenetic trees constructed by IQ-TREE 1.6.9 with 1000 ultrafast bootstrap replicates and 1000 replicates of the Shimodaira-Hasegawa approximate likelihood-ratio test (SH-aLRT) (23).

\section{Transmission Network Analysis}

Transmission network analysis has been described previously (20). Briefly, all the HIV-1 sequences including a dataset of HIV1 reference sequences from the Los Alamos National Laboratory HIV-1 database were aligned. The transmission clusters was identified by HIV Transmission Cluster Engine (HIV-TRACE) using a genetic distance threshold of $1.5 \%$ (24) or Cluster Picker with an intra-cluster genetic distance threshold of $4.5 \%$ $(25,26)$. The position of nodes in the transmission clusters were determined by nodal centrality indicators including degree, betweenness, closeness, clustering coefficient, and radiality, which were measured using NetworkAnalyzer 2.7 implemented in Cytoscape 3.7.0.13 (20, 27). K-shell (Ks) score, a measure of the cohesiveness of a subset of individuals among whom there are stronger, more direct, or more frequent ties than between other subgroups within the same network, was used to identify the hub node (28). Nodes with high Ks are more prone to infection and to be the most influential spreaders during epidemics (29-31). A novel graph theoretic clustering algorithm, Molecular Complex Detection (MCODE) implemented in Cytoscape 3.7.0.13, was adapted to identify the densely connected sub-networks in the large HIV-1 transmission clusters (32). 


\section{Statistical Analysis}

To compare the difference of the centrality metrics and Ks score of nodes between HIV-infected MSM with or without syphilis testing, the Wilcoxon signed-rank test was adapted to estimate the statistical significance in all the HIV-infected MSM or in 1:1 matched pairs of MSM generated by the propensity score matching (PSM) method $(33,34)$. We compared their epidemiological data at HIV-1 diagnosis and further adapted the logistic regression analysis to explore the association between syphilis testing and factors related to HIV-1 transmission. All the candidate variables with a $p$-value of $<0.1$ in the univariate model were sequentially included in a binary multivariate model using the stepwise forward method to estimate the association with syphilis testing. Multivariate Cox proportional hazards regression analysis was used to identify the independent factors associated with the engagement of ART and the speed of ARTrelated $\mathrm{CD}^{+} \mathrm{T}$ cell recovery. SPSS version 25.0 (SPSS Inc., Chicago, IL, USA) and R software version 4.0.2 were used to perform the statistical analysis.

\section{RESULTS}

\section{MSM Without Syphilis Testing Were More Often Located in the Big HIV-1 Transmission Clusters}

A total of 729 HIV-1 sequences obtained from newly diagnosed HIV-infected MSM were used to construct HIV1 molecular transmission networks using HIV-TRACE. Among them, $638 \mathrm{HIV}-1$ sequences were located in 76 clusters (Supplementary Figure 2A) and 27 (35.5\%) clusters contained only 2 individuals. The proportion of cluster sizes of $3-5,6-10$, and $>10$ was $30.3,15.8$, and $18.4 \%$, respectively (Supplementary Figure 2B). For the small clusters with fewer than 5 members, $70-82 \%$ of them contained at least one recipient of syphilis testing while only $44-48 \%$ of these clusters contained MSM without syphilis testing. In contrast, for big clusters with more than 6 members, the proportion of the clusters that contained MSM without syphilis testing dramatically increased and further reached similar levels to the clusters containing the recipients of syphilis testing (Supplementary Figure 2B). Furthermore, in the small clusters, the subjects were dominated by MSM with syphilis testing (62-63\%) while the number of MSM with or without syphilis testing were almost equal in the big clusters (Supplementary Figure 2C). These results indicated that MSM without syphilis testing were more often located in the big clusters rather than in the small clusters of HIV-1 transmission.

Furthermore, Cluster Picker analysis identified 45 HIV-1 transmission clusters (Table 1, Supplementary Figure 3). MSM infected with HIV-1 CRF55_01B, CRF 01_AE, and CRF 07_BC were more likely to be clustered than subtype B or other HIV-1 genotypes ( $p<0.05$, Table 1). However, the composition of HIV1 genotypes and the demographic characteristics of the clusters identified by HIV-TRACE and Cluster Picker were not different (Table 1).

\section{MSM Without Syphilis Testing Were More Efficient in HIV-1 Transmission}

To further identify the key population driving HIV-1 transmission and to provide molecular evidence about the role of HIV-infected MSM without syphilis testing in HIV-1 transmission, we conducted centrality analysis and found that the following centrality indicators were significantly larger for MSM without syphilis testing than for the recipients of syphilis testing: the median degree (2.000, IQR $1.000-4.375$ vs. 1.000 , IQR $0.000-3.813, P=0.004)$, the median radiality (1.000, $0.748-1.000$ vs. $0.752,0.000-1.000, P=0.008)$, the clustering coefficient $(0.645,0.000-1.000$ vs. $0.000,0.000-0.792, P=0.009)$, and the closeness centrality $(1.000,0.548-1.000$ vs. $0.557,0.000-$ $1.000, P=0.007)$, but no significant difference was observed for the betweenness centrality ( $P=0.399$, Table 2, Model 1$)$. To reduce the potential bias due to the heterogeneity between the MSM with or without syphilis testing, we further analyzed the centrality indicators using 1:1 matched pairs of the MSM with or without syphilis testing based on PSM methodology to adjust the potential differences of the baseline characteristics (Supplementary Table 1). Similar results were obtained (Table 2, Model 2). These results indicated the central position of MSM without syphilis testing in the HIV-1 transmission networks and revealed their active role in HIV-1 transmission.

Furthermore, we adapted a node influence measurement by calculating the Ks score of a node to identify the most influential spreaders in the HIV-1 transmission networks. Interestingly, we found that median Ks scores were statistically greater for the MSM without syphilis testing than those with syphilis testing (7.000, IQR 4.940-21.700 vs. 5.786, IQR 0.000-21.764, $P=0.022$, Table 2, Figure 1). Then, we used MCODE analysis to analyze the densely connected sub-networks in the large transmission clusters and identified 33 key sub-networks and 8 seed nodes (Figure 1). Of note, the seed nodes were more frequently identified to be MSM without syphilis testing than those with syphilis screening (7/8 vs. $1 / 8)$ although the difference did not reach statistical significance $(P=0.069$, Table 2 , Model 1). These results reiterated that MSM without syphilis testing may be a specific subgroup of MSM with more efficient HIV1 transmission.

\section{MSM With and Without Syphilis Testing Were Different Subgroups}

Although free syphilis testing was provided upon the diagnosis of HIV-1 infection, in our study, 56.7\% of HIV-infected MSM refused syphilis testing at the time of HIV-1 diagnosis. For those with or without syphilis testing, the significant differences were observed with regard to the occupation, the number of sex partners in the past 6 months, the history of STIs, and the stage of HIV-1 infection (Table 3). For example, 20.1\% of the MSM without syphilis testing were unemployed or took non-skilled jobs, and $23.7 \%$ of them did not report their occupation while $77.5 \%$ of the recipients of syphilis testing had skilled/professional jobs or were students $(P<$ 0.001). Furthermore, $42.4 \%$ of MSM without syphilis testing reported only one sex partner during the past 6 months 
TABLE 1 | Demographic characteristics of HIV-infected MSM clustered by HIV-TRACE or Cluster Picker\& .

\begin{tabular}{|c|c|c|c|c|c|c|}
\hline Characteristics & & $\begin{array}{c}\text { Total } \\
(n=729, \%)\end{array}$ & \multicolumn{2}{|c|}{ HIV-TRACE $(n=638)$} & \multicolumn{2}{|c|}{ Cluster picker $(n=689)$} \\
\hline \multirow[t]{2}{*}{ Screening for syphilis } & Yes & $316(43.3)$ & $284 / 638(44.5)$ & 284/316 (89.9) & $300 / 689$ (43.5) & 300/316 (94.9) \\
\hline & No & $413(56.7)$ & $354 / 638(55.5)$ & $354 / 413(85.7)$ & $389 / 689$ (56.5) & 389/413 (94.2) \\
\hline & $\geq 41$ & $79(10.8)$ & 66/638 (10.3) & 66/79 (83.5) & 71/689 (10.3) & 71/79 (89.9) \\
\hline \multirow[t]{3}{*}{ Marital status } & Single & $517(70.9)$ & 452/638 (70.8) & $452 / 517(87.4)$ & 489/689 (71.0) & 489/517 (94.6) \\
\hline & Married & $165(22.6)$ & 149/638 (23.4) & 149/165 (90.3) & 156/689 (22.6) & 156/165 (94.5) \\
\hline & $\begin{array}{l}\text { Divorced/separated/ } \\
\text { widowed }\end{array}$ & $47(6.4)$ & 37/638 (5.8) & $37 / 47(78.7)$ & 44/689 (6.4) & 44/47 (93.6) \\
\hline \multirow[t]{4}{*}{ Occupation } & $\begin{array}{l}\text { Skilled/ professional } \\
\text { work }\end{array}$ & $428(58.7)$ & $371 / 638(58.2)$ & $371 / 428(86.7)$ & 402/689 (58.3) & 402/428 (93.9) \\
\hline & $\begin{array}{l}\text { Unemployment/unskilled } \\
\text { work }\end{array}$ & $133(18.2)$ & 113/638 (17.7) & 113/133 (85) & 125/689 (18.1) & 125/133 (94) \\
\hline & Students & $49(6.7)$ & 46/638 (7.2) & 46/49 (93.9) & 46/689 (6.7) & 46/49 (93.9) \\
\hline & Not disclosed & $119(16.3)$ & 108/638 (16.9) & 108/119 (90.8) & 116/689 (16.8) & $116 / 119(97.5)$ \\
\hline \multirow[t]{2}{*}{ Ethnicity } & Han & $710(97.4)$ & 623/638 (97.6) & $623 / 710(87.7)$ & $671 / 689(97.4)$ & $671 / 710(94.5)$ \\
\hline & Others & $19(2.6)$ & $15 / 638(2.4)$ & 15/19 (78.9) & 18/689 (2.6) & $18 / 19(94.7)$ \\
\hline \multirow{2}{*}{$\begin{array}{l}\text { Number of sex partners } \\
\text { in the past } 6 \text { months }\end{array}$} & $\leq 1$ & $210(28.8)$ & 186/638 (29.2) & 186/210 (88.6) & 201/689 (29.2) & 201/210 (95.7) \\
\hline & $2 \sim 5$ & 316 (43.3) & 281/638 (44.0) & 281/316 (88.9) & 300/689 (43.5) & 300/316 (94.9) \\
\hline \multirow{3}{*}{ HIV-1 genotype } & CRF 55_01B & $115(15.8)$ & $112 / 638(17.6)^{\star}$ & $112 / 115(97.4)^{\star}$ & $110 / 689(16.0)^{\star}$ & $110 / 115(95.7)^{\star}$ \\
\hline & Subtype B & $61(8.4)$ & 30/638 (4.7) & 30/61 (49.2) & $44 / 689(6.4)^{\star}$ & $44 / 61(72.1)^{\star}$ \\
\hline & Others & $25(3.4)$ & $9 / 638(1.4)^{*}$ & $9 / 25(36.0)^{\star}$ & 12/689 (1.7) & 12/25 (48) \\
\hline \multirow{4}{*}{$\begin{array}{l}\text { Baseline CD4+ counts } \\
\left(\text { cell/mm } \mathrm{mm}^{3}\right)\end{array}$} & $<200$ & $111(15.2)$ & $92 / 638(14.4)$ & $92 / 111(82.9)$ & $104 / 689(15.1)$ & $104 / 111(93.7)$ \\
\hline & $200 \sim 349$ & 235 (32.3) & 212/638 (33.3) & 212/235 (90.2) & 228/689 (33.1) & 228/235 (97) \\
\hline & $350 \sim 499$ & $229(31.5)$ & 200/638 (31.4) & 200/229 (87.3) & 216/689 (31.4) & $216 / 229(94.3)$ \\
\hline & $\geq 500$ & $153(21.0)$ & 133/638 (20.9) & 133/153 (86.9) & 140/689 (20.3) & 140/153 (91.5) \\
\hline \multirow[t]{2}{*}{ Disease stage ${ }^{\#}$} & HIV-1 infection & $499(68.4)$ & 440/638 (69.0) & 440/499 (88.2) & 470/689 (68.2) & 470/499 (94.2) \\
\hline & AIDS & 230 (31.6) & 198/638 (31.0) & 198/230 (86.1) & 219/689 (31.8) & 219/230 (95.2) \\
\hline
\end{tabular}

\& HIV-infected MSM were collected from 2008 to 2012 in Guangzhou, China.

*Statistically significant difference $(P<0.05$, Chi-square tests) between clustered and non-clustered subjects.

\#The definition and diagnosis of AIDS are based on the Guidelines for Diagnosis and Treatment of HIVIAIDS in China (2005).

MSM, men who have sex with men; STI, sexually transmitted infection; HIV-1, human immunodeficiency virus type one; AIDS, acquired immune deficiency syndrome.

whereas multiple sex partners were recorded in $88.9 \%$ of MSM with syphilis testing $(p<0.001)$. In addition, acquired immunodeficiency syndrome (AIDS) was recorded slightly more frequently in the MSM without syphilis testing than the recipients of syphilis testing ( 35.6 vs. $26.6 \%, p=0.012$ ). The percentage of past STIs was also different between MSM with or without syphilis testing $(p<0.001)$ in part due to the difference in regard to the awareness of their STIs (57.6 vs. $42.4 \%, p=0.001$, Supplementary Table 2). Multivariable logistic regression analysis also confirmed that MSM who did not report 
TABLE 2 | Centrality analysis of HIV-1 transmission networks for MSM with or without syphilis testing during 2008-2012 in Guangzhou, China.

\begin{tabular}{|c|c|c|c|c|c|c|}
\hline \multirow[t]{2}{*}{ Centrality indicators $^{a}$} & \multicolumn{3}{|c|}{ Syphilis screening ( $n, \%$ or IQR, Model $\left.1^{b}\right)$} & \multicolumn{3}{|c|}{ Syphilis screening ( $n, \%$ or IQR, Model $\left.2^{c}\right)$} \\
\hline & Yes $(n=413)$ & No $(n=316)$ & $P$ & Yes $(n=220)$ & No $(n=220)$ & $P^{d}$ \\
\hline Number clustered & $284(89.9)$ & $354(85.7)$ & 0.092 & $188(85.5)$ & $186(84.5)$ & 0.789 \\
\hline Closeness centrality & $0.557(0.000,1.000)$ & $1.000(0.548,1.000)$ & $0.007^{\star \star}$ & $0.499(0.000,0.683)$ & $0.742(0.578,0.917)$ & $0.002^{\star \star}$ \\
\hline Clustering coefficient & $0.000(0.000,0.792)$ & $0.645(0.000,1.000)$ & $0.009^{\star \star}$ & $0.556(0.000,0.768)$ & $0.708(0.564,0.966)$ & $0.017^{\star \star}$ \\
\hline Degree & $1.000(0.000,3.813)$ & $2.000(1.000,4.375)$ & $0.004^{\star \star}$ & $2.500(1.000,5.667)$ & $7.750(4.000,12.000)$ & $0.004^{\star \star}$ \\
\hline Radiality & $0.752(0.000,1.000)$ & $1.000(0.748,1.000)$ & $0.008^{\star \star}$ & $0.737(0.000,0.886)$ & $0.905(0.858,0.944)$ & $0.003^{\star \star}$ \\
\hline Betweenness centrality & $0.000(0.000,0.000)$ & $0.000(0.000,0.003)$ & 0.399 & $0.002(0.000,0.023)$ & $0.006(0.000,0.109)$ & 0.363 \\
\hline Ks of sub-networks & $5.786(0.000,21.764)$ & $7.000(4.940,21.700)$ & $0.022^{*}$ & $2.392(0.000,6.693)$ & $5.970(4.000,7.275)$ & $0.011^{*}$ \\
\hline Number of seed nodes & 1.0 & 7.0 & 0.069 & 1.0 & 2.0 & - \\
\hline
\end{tabular}

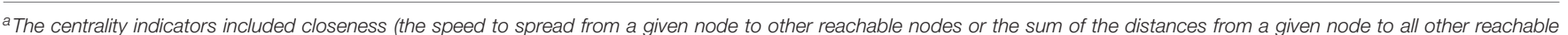

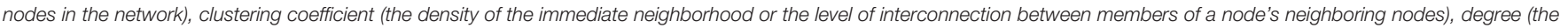

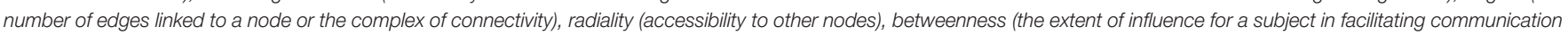

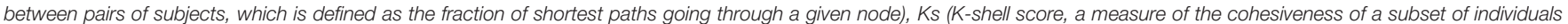

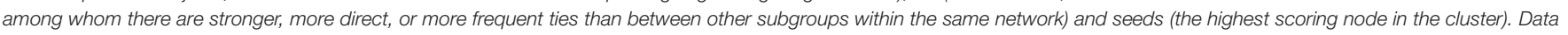
are the median and their interquartile range (IQR) for the abnormal distribution of indicators.

${ }^{b}$ Model 1: Comparison and analysis were conducted in the two groups of MSM with or without syphilis screening among all the HIV-1 transmission clusters.

${ }^{c}$ Model 2: Comparison and analysis were conducted between the clusters with propensity score-matched pairs of MSM with or without syphilis screening.

${ }^{d}$ Statistical significance was calculated using a Wilcoxon signed-rank test. $A P<0.05$ is statistically significant. ${ }^{\star} P<0.05$; ${ }^{\star \star} P<0.01$.

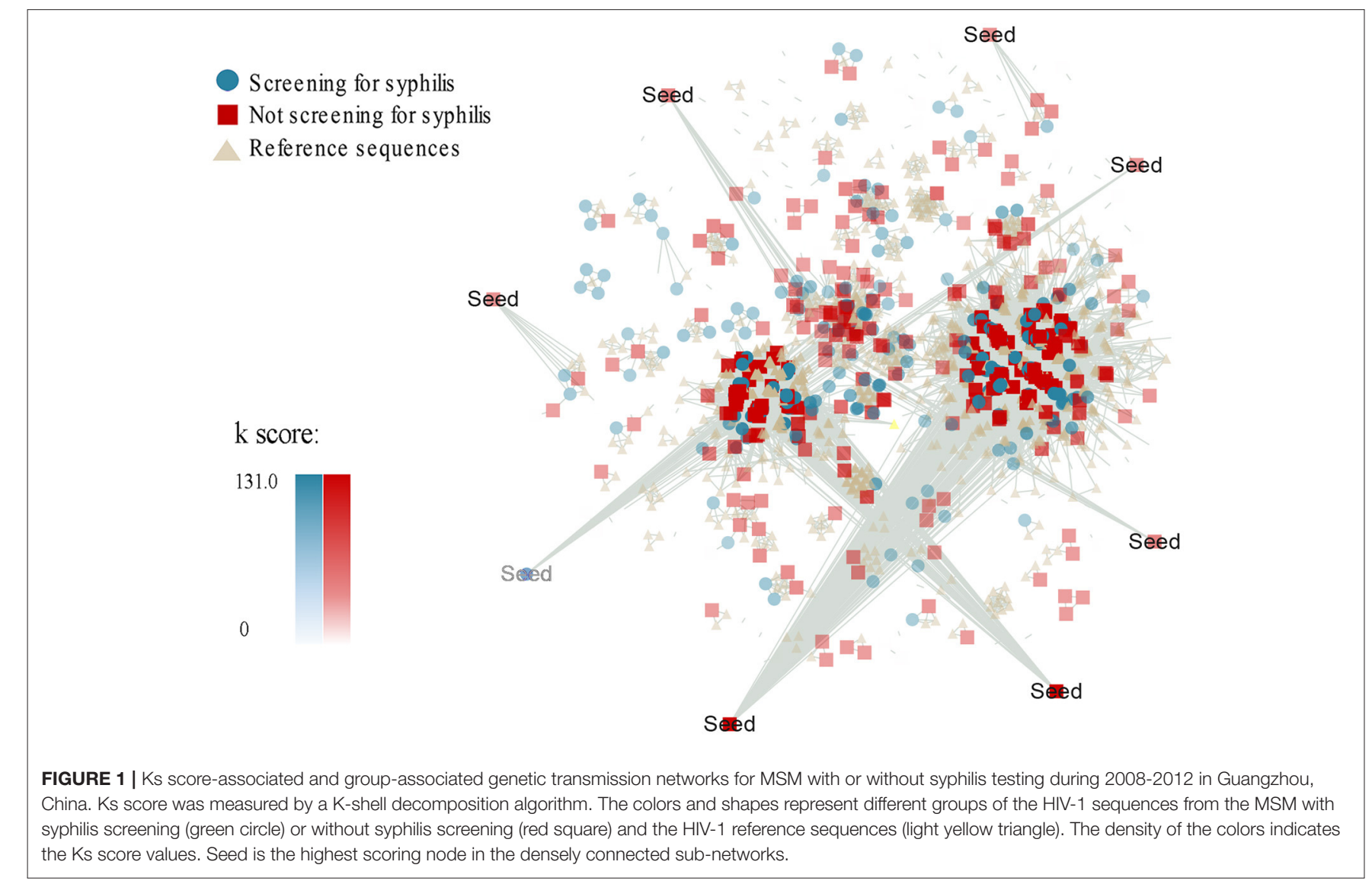

their occupations were most unlikely to receive syphilis testing [adjusted odds ratio $(\mathrm{aOR})=4.468, p<0.001$, Table 4]. In addition, syphilis testing was less likely to be accepted by those who disclosed their history of STIs than those who did not know their STIs ( $\mathrm{aOR}=0.466, p=0.001$, Table 4), Furthermore,
MSM without syphilis testing were less likely to have multiple sex partners $(p<0.001$, Table 4$)$. Of note, the distribution of ethnicity $(p=0.129)$ and HIV-1 genotypes $(p=0.316)$ were not statistically different between MSM with and without syphilis testing (Table 3). 
TABLE 3 | Comparison of demographic characteristics for HIV-infected MSM with or without syphilis screening from 2008 to 2012 in Guangzhou, China.

\begin{tabular}{|c|c|c|c|c|}
\hline \multirow[t]{2}{*}{ Characteristics } & & \multicolumn{2}{|c|}{ Syphilis screening $(n, \%)$} & \multirow[t]{2}{*}{$P$-value } \\
\hline & & Yes $(n=316)$ & No $(n=413)$ & \\
\hline \multirow[t]{3}{*}{ Age group (years) } & $16-30$ & $193(61.1)$ & $236(57.1)$ & $0.528^{d}$ \\
\hline & $31-40$ & $92(29.1)$ & $129(31.2)$ & \\
\hline & $\geq 41$ & $31(9.8)$ & $48(11.6)$ & \\
\hline \multirow[t]{3}{*}{ Marital status } & Single & $219(69.3)$ & $298(72.2)$ & $0.693^{\mathrm{e}}$ \\
\hline & Married & $76(24.1)$ & $89(21.5)$ & \\
\hline & Divorced/separated/widowed & $21(6.6)$ & $26(6.3)$ & \\
\hline \multirow[t]{3}{*}{ Education level } & Lower than senior high school & $78(24.7)$ & $89(21.5)$ & $0.434^{e}$ \\
\hline & Senior high school & $103(32.6)$ & $129(31.2)$ & \\
\hline & Junior college or higher & $135(42.7)$ & $195(47.2)$ & \\
\hline \multirow[t]{4}{*}{ Occupation } & Skilled/professional work & $219(69.3)$ & $209(50.6)$ & $<0.001^{\star \star \star \mathrm{e}}$ \\
\hline & Unemployment/unskilled work & $50(15.8)$ & $83(20.1)$ & \\
\hline & Students & $26(8.2)$ & $23(5.6)$ & \\
\hline & Not disclosed & $21(6.6)$ & $98(23.7)$ & \\
\hline \multirow[t]{2}{*}{ Ethnicity } & Han & $331(98.4)$ & 339 (96.6) & 0.129 \\
\hline & Others & $5(1.6)$ & $14(3.4)$ & \\
\hline \multirow[t]{3}{*}{ Number of sex partners in the past 6 months } & $\leq 1$ & $35(11.1)$ & $175(42.4)$ & $<0.001^{\star \star \star d}$ \\
\hline & $2 \sim 5$ & $148(46.8)$ & $168(40.7)$ & \\
\hline & $>5$ & $133(42.1)$ & $70(16.9)$ & \\
\hline \multirow[t]{3}{*}{ STIs history } & Yes & $35(11.1)$ & $66(16.0)$ & $<0.001^{\star \star \star e}$ \\
\hline & No & 99 (31.3) & $172(41.6)$ & \\
\hline & Unknown & $182(57.6)$ & $175(42.4)$ & \\
\hline \multirow[t]{5}{*}{ HIV-1 genotype } & CRF 07_BC & $128(40.5)$ & $137(33.2)$ & $0.316^{e}$ \\
\hline & CRF 01_AE & $109(34.5)$ & $154(37.3)$ & \\
\hline & CRF 55_01B & $47(14.9)$ & $68(16.5)$ & \\
\hline & Subtype B & $22(7.0)$ & $39(9.4)$ & \\
\hline & Others & $10(3.2)$ & $15(3.6)$ & \\
\hline \multirow[t]{4}{*}{ Baseline CD4 ${ }^{+}$counts $\left(\right.$cell $/ \mathrm{mm}^{3}$ ) } & $<200$ & $43(13.6)$ & $69(16.7)$ & $0.184^{d}$ \\
\hline & $200 \sim 349$ & $95(30.1)$ & $140(33.9)$ & \\
\hline & $350 \sim 499$ & $101(32.0)$ & $128(31.0)$ & \\
\hline & $\geq 500$ & $77(24.4)$ & $76(18.4)$ & \\
\hline \multirow[t]{2}{*}{ Disease stage ${ }^{a}$} & HIV-1 infection & $232(73.4)$ & $267(64.6)$ & $0.012^{\star \mathrm{e}}$ \\
\hline & AIDS & $84(26.6)$ & $146(35.4)$ & \\
\hline \multirow[t]{2}{*}{ ART initiation after diagnosis ${ }^{b}$} & Yes & $156(55.5)$ & $249(69.4)$ & $<0.001^{\star \star \star \mathrm{e}}$ \\
\hline & No & $125(44.5)$ & $110(30.6)$ & \\
\hline Median time from HIV-1 diagnosis to ART initiation (IQR, years) & & $3.0(1.2-3.7)$ & $2.5(0.7-3.7)$ & $0.037^{\star f}$ \\
\hline \multirow[t]{2}{*}{$\mathrm{CD}^{+} \mathrm{T}$ cell count recovery after $\mathrm{ART}^{\mathrm{C}}$} & Yes & $78(84.8)$ & $103(73.6)$ & $0.044^{\star \mathrm{e}}$ \\
\hline & No & $14(15.2)$ & $37(26.4)$ & \\
\hline Median time to CD4 ${ }^{+} \mathrm{T}$ cell count recovery (IQR, months) ${ }^{\mathrm{C}}$ & & $5.1(1.8-8.5)$ & $9.1(4.3-13.9)$ & $0.124^{f}$ \\
\hline
\end{tabular}

${ }^{a}$ The definition and diagnosis of AIDS are based on the Guidelines for Diagnosis and Treatment of HIVIAIDS in China (2005).

${ }^{b}$ ART-naive MSM with at least one follow-up visit data $(n=640)$.

${ }^{c} \mathrm{CD} 4{ }^{+} \mathrm{T}$ cell recovery is defined as the increase of $\mathrm{CD} 4^{+}$cell count from $<350$ before ART to $>350 \mathrm{cells} / \mathrm{mm}$ after ART.

${ }^{d}$ Kruskal-Wallis tests; ${ }^{e}$ Chi-square tests; ${ }^{f}$ Mann-Whitney U-tests. $A P<0.05$ is statistically significant. ${ }^{\star} P<0.05 ;{ }^{* \star \star} P<0.001$.

MSM, men who have sex with men; STI, sexually transmitted infection; HIV-1, human immunodeficiency virus type one; AIDS, acquired immune deficiency syndrome.

\section{Syphilis Testing Was Not Associated With ART Initiation and ART-Related CD4 Cell Recovery}

To investigate the difference between MSM with or without syphilis testing in the compliance of HIV-1 care, in particular the engagement of ART and the response to ART, we summarized the baseline characteristics between the subjects with or without ART (Supplementary Table 3), and found that the percentage of ART engagement was slightly higher in those without syphilis testing than the recipients of syphilis testing (69.4 vs. 55.5\%, $P=0.001$, Supplementary Table 3). Kaplan-Meier analysis also indicted that MSM without syphilis testing started ART earlier than the recipients of syphilis testing $(P=0.003$, Figure 2A). To 
TABLE 4 | Factors associated with no syphilis testing among HIV-infected MSM from 2008 to 2012 in Guangzhou, China.

\begin{tabular}{|c|c|c|c|c|c|c|c|}
\hline Characteristics & & Jnadjusted $P$-value ${ }^{a}$ & Unadjusted OR & $90 \%$ C.I. & Adjusted $P$-value ${ }^{b}$ & Adjusted OR & 95\% C.I. \\
\hline \multirow[t]{4}{*}{ Occupation } & $\begin{array}{l}\text { Skilled/professional } \\
\text { work }\end{array}$ & $<0.001$ & Reference & & $<0.001$ & Reference & \\
\hline & $\begin{array}{l}\text { Unemployment/unskilled } \\
\text { work }\end{array}$ & 0.007 & 1.739 & $1.245,2.431$ & 0.080 & 1.483 & $0.954,2.306$ \\
\hline & Students & 0.802 & 0.927 & $0.564,1.524$ & 0.446 & 0.778 & $0.408,1.484$ \\
\hline & Not disclose & $<0.001$ & 4.890 & $3.193,7.489$ & $<0.001$ & 4.468 & $2.602,7.675$ \\
\hline \multirow{3}{*}{$\begin{array}{l}\text { Number of sexual } \\
\text { partners in the } \\
\text { past } 6 \text { months }\end{array}$} & $\leq 1$ & $<0.001$ & Reference & & $<0.001$ & Reference & \\
\hline & $2 \sim 5$ & 0.004 & 1.689 & $1.254,2.274$ & $<0.001$ & 0.192 & $0.123,0.302$ \\
\hline & $>5$ & $<0.001$ & 3.799 & $2.308,6.254$ & $<0.001$ & 0.097 & $0.060,0.159$ \\
\hline \multirow[t]{2}{*}{ STIs history } & Known & $<0.001$ & Reference & & $<0.001$ & Reference & \\
\hline & Unknown & $<0.001$ & 0.541 & $0.422,0.694$ & $<0.001$ & 0.466 & $0.332,0.655$ \\
\hline \multirow[t]{2}{*}{ Disease stage } & HIV-1 infection & 0.012 & Reference & & 0.072 & Reference & \\
\hline & AIDS & 0.012 & 1.510 & $1.154,1.977$ & 0.072 & 1.392 & $0.970,1.997$ \\
\hline
\end{tabular}

further explore the reasons for the difference of ART initiation, we adapted multivariate Cox proportional hazards regression analysis and found that syphilis testing was not an independent factor associated with ART initiation (adjusted $p=0.233$, Table 5). The factors associated with the time to initiate ART included age, HIV-1 genotypes, the time of HIV-1 diagnosis, baseline $\mathrm{CD}^{+}{ }^{+}$cell count, disease stage during HIV-1 diagnosis, and the disclosure of STIs (Table 5). Because STI history was associated with both syphilis testing with an unadjusted OR of 0.541 (Table 4) and ART initiation (unadjusted HR $=0.713$, Table 5), we stratified the MSM population according to the disclosure of STIs in a time-to-event model to avoid confounding the STIs. The result indicated that ART engagement was not affected by syphilis testing in those aware $(P=0.546)$ or unaware of their STI history ( $P=0.141$, Supplementary Figure 4$)$. These results indicated that syphilis testing per se did not affect the initiation of ART among HIV-infected MSM.

Furthermore, the speed of $\mathrm{CD}^{+}{ }^{+} \mathrm{T}$ cell recovery following ART was analyzed among the subjects with baseline CD4 ${ }^{+}$ $\mathrm{T}$ cell count $<350 \mathrm{cell} / \mathrm{mm}^{3}$ and at least two follow-up visit records. Among the $232 \mathrm{HIV}$-infected MSM analyzed, CD4 ${ }^{+}$ cell count increased to $\geq 350$ cells $/ \mathrm{mm}^{3}$ in $84.8 \%(78 / 181)$ and $73.6 \%(103 / 181)$ of the subjects with or without syphilis testing, respectively. However, the difference was marginally significant $(P=0.044$, Supplementary Table 4). Kaplan-Meier analysis indicated that HIV-infected MSM with syphilis testing achieved $\mathrm{CD}^{+}$cell count $>350$ cells $/ \mathrm{mm}^{3}$ significantly earlier than the patients without syphilis testing. The median time was 5.1 months for the recipients of syphilis testing and 9.1 months for those without syphilis testing, respectively $(P=0.047$, Figure 2B). Multivariate Cox proportional hazards regression analysis indicated that syphilis testing did not directly affect the outcome of $\mathrm{CD}^{+} \mathrm{T}$ cell recovery $(P=0.256$, Table 6). In contrast, the speed of $\mathrm{CD} 4^{+} \mathrm{T}$ cell recovery was mainly associated with baseline $\mathrm{CD} 4^{+} \mathrm{T}$ cell counts at the time of HIV-1 diagnosis $(P<0.001)$ or ART initiation $(P<0.001$, Table 6$)$.

\section{DISCUSSION}

Syphilis screening is important for the control of both syphilis and HIV-1 infection. However, a large number of HIV-positive MSM do not receive syphilis testing as recommended $(10,14,15)$. In our study, $56.7 \%$ of newly diagnosed HIV-infected MSM refused to take syphilis testing although it is provided for free in China. Our results are in line with the data obtained from HIV-infected MSM in Shanghai, China where the rate of syphilis testing was approximately 50\% in 2010 (13). A recent online national survey in China also revealed that the acceptance rate of syphilis self-testing was $51.7 \%$ among MSM (35). Of note, the syphilis testing rate was suboptimal in the United States where only $68.3 \%$ of HIV-positive MSM took this testing during 2017-2018 (36). Though several studies have presented the sociodemographic characteristics of MSM with and without syphilis testing uptake $(13,35,37)$, few studies investigated the impact of MSM who refuse to take syphilis testing on HIV-1 transmission and ART treatment partly because of the difficulty of identifying the subgroups of HIV-infected persons and precisely tracing their HIV-1 transmission.

Fortunately, HIV-1 genetic network analysis has been welldocumented to be able to identify the subgroup of persons with specific significance in HIV-1 transmission, and to provide precise prevention measures targeting the specific subpopulation $(38,39)$. In our study, we found that the MSM without syphilis testing were more likely to be found in the center of HIV-1 transmission networks and had a more intimate and direct relationship with other MSM according to their 


\section{A Time to HIV treatment initiation}
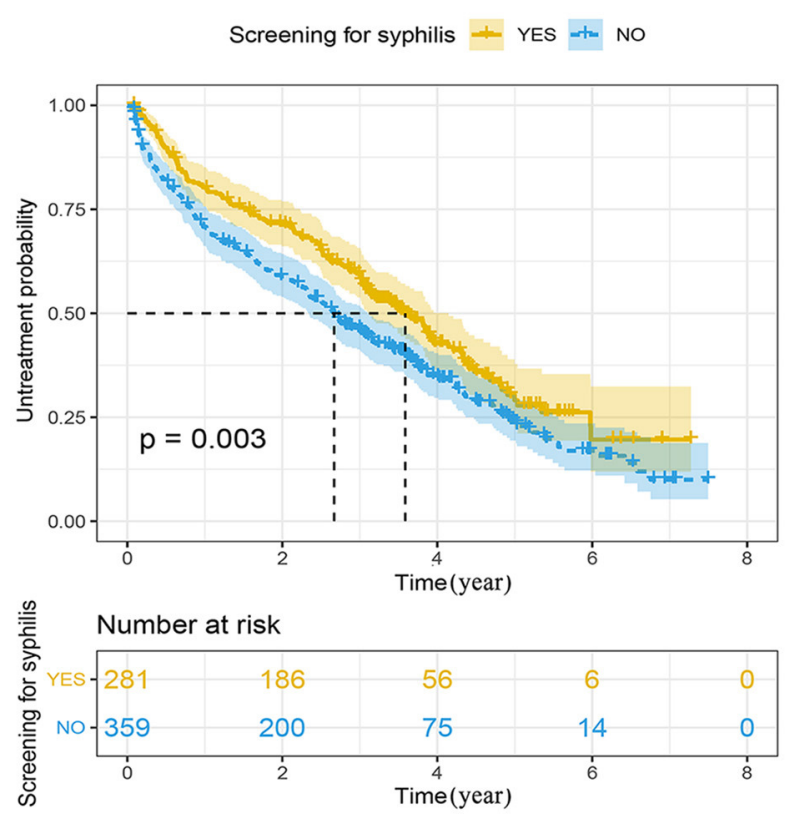

B

CD4+ T-cell recovery following initiation of ART
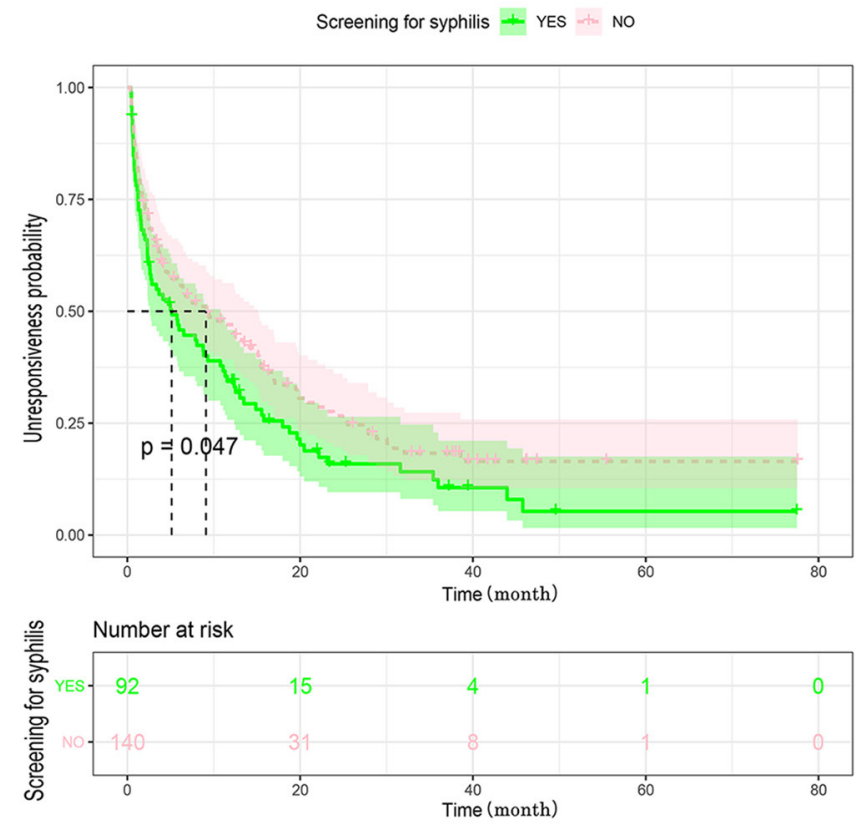

FIGURE 2 | (A) Kaplan-Meier analysis of the time to initiate antiretroviral treatment between MSM with or without syphilis screening in Guangzhou, China, 2008-2012. The date of HIV-1 diagnosis was defined as time zero. The tick marks indicate the participants with censored data. $P$-values were calculated by the log-rank test. The median time to initiate ART was 2.7 years (range 2.3-3.0) for MSM without syphilis testing, and 3.6 years (range 3.1-4.1) for MSM with syphilis screening, respectively. MSM, men who have sex with men; HIV, human immunodeficiency virus. (B) Kaplan-Meier analysis of the time from CD4 ${ }^{+}$count $<350-350$ cells/ $\mu \mathrm{L}$ following ART between MSM with or without syphilis screening. The date of ART initiation was defined as time zero. The tick marks indicate the participants with censored data. P-values were calculated by the log-rank test. The median time from CD4+ T-cell count $<350-\geq 350$ cells/ $\mu \mathrm{L}$ was 9.1 months (range $4.3-13.9$ ) for the patients without syphilis testing, and 5.1 months (range 1.8-8.5) for the patients with syphilis screening.

greater degree, radiality, and clustering coefficient within HIV1 transmission networks. These results indicated that they were prone to contribute to the small world properties rather than in an intermediary form (40-42). Well-documented small world effect is characteristic of fast and efficient information transfer $(40,43)$. The presence of small world effect might be a mirror of efficient HIV-1 transmission among the HIV-infected MSM population who refuse to receive syphilis testing. Furthermore, coreness centrality obtained in the K-shell decomposition process is well-known to be a better measure than the degree to identify the potential influential spreaders in the transmission network (29-31). In our study, K-shell decomposition analysis also confirmed MSM who refuse syphilis testing as a specific subgroup of HIV-infected subjects with an active role in HIV1 transmission. To our best knowledge, this is the first study to adapt HIV-1 transmission network analysis to characterize MSM without syphilis testing and to provide molecular evidence of their important role in enhancing HIV-1 transmission in China.

Our results indicated that such a specific group of MSM may lack knowledge about HIV-1 and syphilis or may not want to test for syphilis due to personal reasons (13). For example, in our study, MSM without syphilis testing were more likely to be unemployed or take non-skilled jobs, previous studies also indicated that non-testing of syphilis was more common among MSM with low HIV knowledge and lower income (13). Of note, we found that $49 \%$ of HIV-infected MSM did not know if they had STIs at the time of HIV-1 diagnosis. Several studies have shown that most persons with syphilis, including up to $44 \%$ of MSM, are unaware of their serostatus of syphilis as they may be asymptomatic for years $(44,45)$ or unwilling to disclose their STI diagnosis (46) and their sexual behaviors $(15,47)$. Our results also showed that MSM without syphilis screening were more likely to be highly connected in the transmission network, indicating that they may have more sexual partners. But unexpectedly, both a national online survey in China and our study found that MSM unwilling to screen for syphilis usually reported fewer sexual partners (35). These results suggested that the selfreported information from HIV-infected MSM may not be true. Therefore, we should interpret with caution the findings obtained through traditional epidemiological analysis according to the self-reported data. In contrast, the molecular epidemiological study was based on the HIV-1 sequences to construct the transmission networks. The results can be more objective and less likely to be affected by personal demographic information.

Our study is of great value for the precise prevention of a HIV-1 epidemic. (1) Our results further indicated that syphilis testing could be used as a proxy marker for the subgroup of MSM without syphilis testing during HIV-1 diagnosis. However, we would like to emphasize that syphilis testing per se was not associated with enhanced HIV-1 transmission and did not promote engagement of ART. As expected, we found that delayed 
TABLE 5 | Factors associated with the time from HIV-1 diagnosis to antiretroviral treatment initiation between HIV-infected MSM with or without syphilis screening during 2008 and 2012 in Guangzhou, China.

\begin{tabular}{|c|c|c|c|c|c|c|c|}
\hline \multicolumn{2}{|c|}{ Characteristics } & \multirow{2}{*}{$\begin{array}{c}\text { Unadjusted } \boldsymbol{P}^{\mathbf{a}} \\
0.003\end{array}$} & \multirow{2}{*}{$\begin{array}{c}\text { Unadjusted HR } \\
\text { Reference }\end{array}$} & \multirow[t]{2}{*}{ 90\% C.I. } & \multirow{2}{*}{$\begin{array}{c}\text { Adjust } \boldsymbol{P}^{\mathbf{b}} \\
0.233\end{array}$} & \multirow{2}{*}{$\begin{array}{l}\text { Adjust HR } \\
\text { Reference }\end{array}$} & \multirow[t]{2}{*}{ 95\% C.I. } \\
\hline Screening for syphilis & Yes & & & & & & \\
\hline & No & 0.003 & 1.353 & $1.143,1.600$ & 0.233 & 1.139 & $0.919,1.412$ \\
\hline \multirow[t]{3}{*}{ Age group (years) } & $16-30$ & 0.002 & Reference & & 0.032 & Reference & \\
\hline & $31-40$ & 0.026 & 1.283 & $1.068,1.543$ & 0.011 & 1.381 & $1.076,1.773$ \\
\hline & $\geq 41$ & 0.001 & 1.62 & $1.264,2.075$ & 0.079 & 1.398 & $0.962,2.032$ \\
\hline \multirow[t]{3}{*}{ Marital status } & Single & 0.005 & Reference & & 0.655 & Reference & \\
\hline & Married & 0.001 & 1.446 & $1.197,1.747$ & 0.734 & 1.051 & $0.789,1.401$ \\
\hline & Divorced/separated/wido & owed0.362 & 1.206 & $0.860,1.690$ & 0.358 & 1.230 & $0.791,1.910$ \\
\hline \multirow[t]{4}{*}{ Occupation } & $\begin{array}{l}\text { Skilled/professional } \\
\text { work }\end{array}$ & 0.025 & Reference & & 0.278 & Reference & \\
\hline & $\begin{array}{l}\text { Unemployment/unskilled } \\
\text { work }\end{array}$ & 0.014 & 1.375 & $1.112,1.700$ & 0.167 & 1.202 & $0.926,1.559$ \\
\hline & Students & 0.873 & 0.966 & $0.679,1.376$ & 0.617 & 1.118 & $0.722,1.731$ \\
\hline & Not disclose & 0.026 & 1.349 & $1.082,1.682$ & 0.087 & 1.275 & $0.966,1.683$ \\
\hline \multirow[t]{2}{*}{ STIs history } & Known & 0.001 & Reference & & 0.030 & Reference & \\
\hline & Unknown & 0.001 & 0.713 & $0.604,0.842$ & 0.030 & 0.795 & $0.646,0.978$ \\
\hline \multirow[t]{5}{*}{ HIV-1 genotypes } & CRF 07_BC & $<0.001$ & 1 & & 0.008 & Reference & \\
\hline & CRF 01_AE & 0.001 & 1.475 & $1.216,1.789$ & 0.056 & 1.269 & $0.994,1.619$ \\
\hline & CRF 55_01B & 0.566 & 0.914 & $0.708,1.182$ & 0.119 & 0.779 & $0.570,1.066$ \\
\hline & Subtype B & 0.002 & 1.777 & $1.304,2.420$ & 0.089 & 1.389 & $0.951,2.030$ \\
\hline & Others & 0.328 & 1.305 & $0.834,2.044$ & 0.182 & 1.445 & $0.841,2.483$ \\
\hline \multirow[t]{4}{*}{ Baseline CD4 ${ }^{+}$counts $\left(\right.$cell $/ \mathrm{mm}^{3}$ ) } & $<200$ & $<0.001$ & Reference & & $<0.001$ & Reference & \\
\hline & $200-350$ & 0.079 & 0.782 & $0.621,0.985$ & 0.222 & 1.214 & $0.889,1.658$ \\
\hline & $351-500$ & $<0.001$ & 0.456 & $0.359,0.578$ & 0.355 & 0.844 & $0.589,1.209$ \\
\hline & $\geq 500$ & $<0.001$ & 0.226 & $0.167,0.304$ & $<0.001$ & 0.417 & $0.272,0.639$ \\
\hline \multirow[t]{2}{*}{ Disease stage } & HIV-1 infection & $<0.001$ & Reference & & $<0.001$ & Reference & \\
\hline & AIDS & $<0.001$ & 0.391 & $0.331,0.461$ & $<0.001$ & 1.847 & $1.415,2.410$ \\
\hline
\end{tabular}

a The univariate Cox proportional hazards regression model. $A P<0.1$ is statistically significant.

${ }^{b}$ The multivariate Cox proportional hazards regression model. A $P<0.05$ is statistically significant.

MSM, men who have sex with men; STI, sexually transmitted infection; HIV, human immunodeficiency virus; AIDS, acquired immune deficiency syndrome; HR, hazard ratio; C.I., confidence interval.

diagnosis of HIV-1 and progressive disease stages were the key factors to affect the engagement of ART treatment. Furthermore, HIV-infected MSM without syphilis screening did not yield more from initiating ART earlier in our study. Consistent with the findings from previous studies, our study illustrated that the baseline $\mathrm{CD}_{4}^{+} \mathrm{T}$ cell count and early HIV-1 diagnosis were the major factors in predicting post-ART recovery of $\mathrm{CD}^{+}$cells (48), but not syphilis screening. (2) Molecular evolution and network analysis are important tools for the precise identification of HIV-1 transmission, which is usually difficult to define via traditional epidemiology surveys, due to the absence or inaccuracy of epidemiological data for HIV-infected individuals. (3) For the precise prevention and intervention of a HIV-1 epidemic, it is necessary to identify and distinguish the subgroups of HIV-infected subjects. We and others used a transmission network and cluster analysis to define potential non-disclosed MSM and their role in enhancing HIV-1 transmission.

Our study was subject to several limitations: (1) the study included 1 center, and was an observational study. Further investigations in multiple centers are needed to verify our findings. (2) The demographic information and the risk factors data such as the history of STIs, and the number of sexual partners in the past 6 months were self-reported although the information may not affect the phylogenetic analysis of HIV-1 sequences. (3) Syphilis screening data were captured from the HIV-1 primary care medical records only. If participants had gone elsewhere (i.e., hospital dermatology clinics) for syphilis screening, it would not be captured. (4) The construction of a HIV-1 transmission network based on only 1 HIV-1 pol gene may not be accurate enough and the data obtained were not authenticated using a wet lab procedure $(20,25)$.

\section{CONCLUSIONS}

HIV-1 transmission network analysis revealed that HIV-infected MSM who refuse to undertake syphilis testing at the time of HIV-1 diagnosis was a specific subgroup of MSM and played an important role in HIV-1 transmission. Therefore, syphilis testing may be a proxy marker for identifying the specific sub-population in HIV-1 transmission. Specific prevention and intervention 
TABLE 6 | Factors associated with the time to CD4+ T-Cell recovery following initiation of ART between HIV-infected MSM with or without syphilis screening during 2008 and 2012 in Guangzhou, China.

\begin{tabular}{|c|c|c|c|c|c|c|c|}
\hline \multicolumn{2}{|c|}{ Characteristics } & \multirow{2}{*}{$\begin{array}{c}\text { Unadjusted } \boldsymbol{P}^{\mathbf{a}} \\
0.048\end{array}$} & \multirow{2}{*}{$\begin{array}{c}\text { Unadjusted HR } \\
\text { Reference }\end{array}$} & \multirow[t]{2}{*}{ 90\% C.I. } & \multirow{2}{*}{$\begin{array}{c}\text { Adjust } \boldsymbol{P}^{\mathbf{b}} \\
0.256\end{array}$} & \multirow{2}{*}{$\begin{array}{l}\text { Adjust HR } \\
\text { Reference }\end{array}$} & \multirow[t]{2}{*}{ 95\% C.I. } \\
\hline Screening for & Yes & & & & & & \\
\hline & No & 0.048 & 0.743 & $0.580,0.951$ & & 0.841 & $0.623,1.134$ \\
\hline \multirow[t]{3}{*}{ HIV-1 genotype } & CRF 07_BC & 0.006 & Reference & & 0.078 & Reference & \\
\hline & CRF 01_AE & 0.001 & 0.596 & $0.457,0.776$ & 0.027 & 0.696 & $0.506,0.959$ \\
\hline & Subtype B & 0.192 & 0.740 & $0.506,1.082$ & 0.691 & 0.911 & $0.577,1.439$ \\
\hline \multirow[t]{2}{*}{ Disease stage } & HIV-1 infection & $<0.001$ & Reference & & 0.476 & Reference & \\
\hline & AIDS & $<0.001$ & 0.271 & $0.209,0.352$ & & 0.870 & $0.593,1.276$ \\
\hline \multirow{3}{*}{$\begin{array}{l}\text { CD4+ counts at } \\
\text { HIV diagnosis } \\
\left(\text { cell } / \mathrm{mm}^{3}\right)\end{array}$} & $<200$ & $<0.001$ & Reference & & $<0.001$ & Reference & \\
\hline & $200-350$ & $<0.001$ & 3.573 & $2.478,5.150$ & 0.013 & 1.922 & $1.149,3.214$ \\
\hline & $351-500$ & $<0.001$ & 8.447 & $6.229,14.326$ & $<0.001$ & 3.841 & $2.15,6.862$ \\
\hline \multirow{2}{*}{$\begin{array}{l}\text { CD4 }{ }^{+} \text {counts at } \\
\text { ART initiation } \\
\left(\text { cell } / \mathrm{mm}^{3}\right)\end{array}$} & $<200$ & $<0.001$ & Reference & & $<0.001$ & Reference & \\
\hline & 200-350 & $<0.001$ & 4.918 & $3.651,6.626$ & $<0.001$ & 2.874 & $1.851,4.464$ \\
\hline \multirow{4}{*}{$\begin{array}{l}\text { Treatment } \\
\text { regimen }^{c}\end{array}$} & $\mathrm{NVP}+3 \mathrm{TC}+\mathrm{AZT}$ & 0.894 & Reference & & & & \\
\hline & $\mathrm{EFV}+3 \mathrm{TC}+\mathrm{AZT}$ & 0.858 & 1.042 & $0.716,1.517$ & & & \\
\hline & EFV+3TC+TDF & 0.668 & 0.911 & $0.638,1.302$ & & & \\
\hline & Others & 0.654 & 0.910 & $0.643,1.287$ & & & \\
\hline
\end{tabular}

a The univariate Cox proportional hazards regression model. A $P<0.1$ is statistically significant.

${ }^{b}$ The multivariate Cox proportional hazards regression model. A $P<0.05$ is statistically significant.

${ }^{c}$ According to the manual for China's National Free Antiretroviral Therapy. 2nd ed. Beijing, China: People's Medical Publishing House 2008.

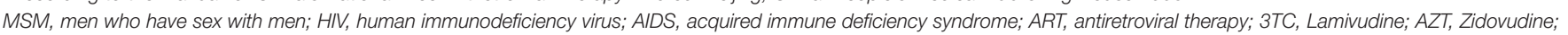
TDF, Tenofovir; EFV, Efavirenz; HR, hazard ratio; C.I., confidence interval.

targeting MSM without syphilis testing are urgently needed. Our results could contribute to evidence-based policy making for the precise intervention of the HIV-1 epidemic.

\section{DATA AVAILABILITY STATEMENT}

The datasets presented in this study can be found in online repositories. The names of the repository/repositories and accession number(s) can be found in the article/Supplementary Materials.

\section{ETHICS STATEMENT}

This study was approved by the Institutional Review Board of Guangzhou CDC (No. 2017030). The patients/participants provided their written informed consent to participate in this study.

\section{AUTHOR CONTRIBUTIONS}

ST and ZH conceived the study. HW, YL, QL and LH collected the data. LH and HY analyzed and interpreted the data. LH and ST wrote the manuscript. All authors reviewed, revised, and approved the final manuscript.

\section{FUNDING}

This work was supported by the National Key R\&D Program of China (Project No. 2018ZX10732401-003) and the Collaborative Innovation Project for Health Care funded by the Bureau of Science and Information Technology of the Guangzhou Municipality (Project Nos. 201604020011, 201704020219, 201707010184, and 201803040002).

\section{SUPPLEMENTARY MATERIAL}

The Supplementary Material for this article can be found online at: https://www.frontiersin.org/articles/10.3389/fmed. 2021.662689/full\#supplementary-material

\section{Supplementary Figure 1 | The flow chat of the study.}

Supplementary Figure 2 | The distribution of HIV-infected MSM with or without syphilis testing across and within the clusters of various sizes from 2008 to 2012 in Guangzhou, China. The HIV-1 transmission clusters identified by HIV-TRACE for MSM with or without syphilis testing during 2008-2012. The colors and shapes represent different groups of the HIV-1 sequences from the MSM with (green circle) or without (red square) syphilis testing and the HIV-1 reference sequences (light yellow triangle). The left and right $y$-axis are the total number of HIV-1 transmission clusters identified in this study and the proportion of these clusters, respectively. The $\mathrm{x}$-axis shows the size of HIV-1 transmission clusters. The dusty blue bar represents the number of clusters while the lines indicate the clusters containing at least one HIV-infected MSM with (green) or without (orange) syphilis 
testing, respectively. The chart shows the coverage of syphilis testing among HIV-1 infected MSM clustered in 4 different cluster sizes. The blue and gray bar represent the proportion of HIV-1 infected MSM with and without syphilis testing in the corresponding clusters, respectively. MSM, men who have sex with men; HIV, human immunodeficiency virus.

Supplementary Figure 3 | Phylogenetic transmission clusters for HIV-1 infected MSM in Guangzhou, China during 2008 and 2012. Phylogenetic HIV-1 transmission clusters identified by Cluster Picker. The outside circle displayed HIV-1 genotypes with different colors, i.e., HIV-1 CRF55_01B (yellow), CRF 01_AE (blue), CRF07_BC (green), subtype B (purple), and other HIV-1 genotypes (gray). The inside circle showed 46 transmission clusters with colored strips while the non-clustered sequences are displayed as white.

Supplementary Figure 4 | Forest plot of the hazard ratio for the factors associated with antiretroviral initiation according to the disclosure of STIs history from 2008 to 2012 in Guangzhou, China. The forest plots summarize the hazard

\section{REFERENCES}

1. Read P, Fairley CK, Chow EP. Increasing trends of syphilis among men who have sex with men in high income countries. Sex Health. (2015) 12:15563. doi: 10.1071/SH14153

2. Centers for Disease Control and Prevention. Sexually Transmitted Disease Surveillance, 2019. (2021). Atlanta, GA: Department of Health and Human Services. Available online at: https://www.cdc.gov/std/syphilis/stdfact-msmsyphilis.htm

3. Wu Z, Xu J, Liu E, Mao Y, Xiao Y, Sun X, et al. HIV and syphilis prevalence among men who have sex with men: a cross-sectional survey of 61 cities in China. Clin Infect Dis. (2013) 57:298-309. doi: 10.1093/cid/cit210

4. Buchacz K, Patel P, Taylor M, Kerndt P, Byers R, Holmberg S, et al. Syphilis increases HIV viral load and decreases CD4 cell counts in HIVinfected patients with new syphilis infections. AIDS. (2004) 18:20759. doi: 10.1097/00002030-200410210-00012

5. Wu MY, Gong HZ, Hu KR, Zheng H-y, Wan X, Li J. Effect of syphilis infection on HIV acquisition: a systematic review and meta-analysis. Sex Transm Infect. (2020) 1-9. doi: 10.1136/sextrans-2020-054706

6. Karp G, Schlaeffer F, Jotkowitz A, Riesenberg K. Syphilis and HIV coinfection. EurJ Internal Med. (2009) 20:9-13. doi: 10.1016/j.ejim.2008. 04.002

7. Tuite AR, Fisman DN, Mishra S. Screen more or screen more often? Using mathematical models to inform syphilis control strategies. BMC Public Health. (2013) 13:1-13. doi: 10.1186/1471-2458-13-606

8. Fairley CK, Law M, Chen MY. Eradicating syphilis, hepatitis C and HIV in MSM through frequent testing strategies. Curr Opin Infect Dis. (2014) 27:56-61. doi: 10.1097/QCO.0000000000000020

9. Tuite AR, Burchell AN, Fisman DN. Cost-effectiveness of enhanced syphilis screening among HIV-positive men who have sex with men: a microsimulation model. PLoS ONE. (2014) 9:e101240. doi: 10.1371/journal.pone.0101240

10. Tucker JD, Cohen MS. China's syphilis epidemic: epidemiology, proximate determinants of spread, and control responses. Curr Opin Infect Dis. (2011) 24:50-5. doi: 10.1097/QCO.0b013e32834204bf

11. Chow EPF, Wilson DP, Zhang L. HIV and syphilis co-infection increasing among men who have sex with men in China: a systematic review and metaanalysis. PLoS ONE. (2011) 6:e22768. doi: 10.1371/journal.pone.0022768

12. Chen XS. Challenges in responses to syphilis epidemic. Lancet Infect Dis. (2017) 17:793-4. doi: 10.1016/S1473-3099(17)30327-4

13. Hall CDX, Luu M, Nehl EJ, He N, Zheng T, Haardörfer R, et al. Do the same socio-demographic variables predict testing uptake and sero-status? HIV and syphilis among an observational sample of Chinese men who have sex with men in Shanghai, China. Int J STD AIDS. (2020) 31:93949 doi: 10.1177/0956462420909733

14. Ong JJ, Liao M, Lee A, Fu H, Pan SW, Tang W, et al. Bridging the HIVsyphilis testing gap: dual testing among men who have sex with men living in China. Sex Transm Infect. (2019) 95:251-3. doi: 10.1136/sextrans-2018053527 ratios (black squares) and their 95\% confidential intervals (Cis, horizontal lines), as well as $P$-values for the interaction between ART initiation and the subgroup variables. A $P$-value $<0.05$ is statistically significant. ${ }^{*} P<0.05$; ${ }^{* *} P<0.01$; ${ }^{* * *} P$ $<0.001$. MSM, men who have sex with men; STI, sexually transmitted infection; HIV, human immunodeficiency virus; AIDS, acquired immune deficiency syndrome.

Supplementary Table 1 | Baseline characteristics of propensity-matched HIV-infected MSM diagnosed from 2008 to 2012 in Guangzhou, China.

Supplementary Table 2 | Different percentage of STIs history between MSM with or without syphilis testing from 2008 to 2012 in Guangzhou, China.

Supplementary Table 3 | Characteristics of HIV-infected MSM with or without antiviral treatment during 2008 and 2012 in Guangzhou, China.

Supplementary Table 4 | Differences between ART-treated MSM with or without CD4 ${ }^{+}$T Cell recovery during 2008 and 2012 in Guangzhou, China
15. Ong JJ, Fu H, Pan S, Smith MK, Wu D, Wei C, et al. Missed opportunities for human immunodeficiency virus and syphilis testing among men who have sex with men in China: a cross-sectional study. Sex Transm Dis. (2018) 45:382-6. doi: 10.1097/OLQ.0000000000000773

16. Shang H, Zhang L. MSM and HIV-1 infection in China. Nat Sci Rev. (2015) 2:388-91. doi: 10.1093/nsr/nwv060

17. Campbell EM, Jia H, Shankar A, Hanson D, Luo W, Masciotra S, et al. Detailed transmission network analysis of a large opiate-driven outbreak of HIV infection in the United States. J Infect Dis. (2017) 216:105362. doi: 10.1093/infdis/jix307

18. Ferraz de Arruda G, Barbieri A, Rodríguez P, Moreno Y, da F. Costa L, Rodrigues F. Role of centrality for the identification of influential spreaders in complex networks. Phys Rev E. (2014) 90:032812. doi: 10.1103/PhysRevE.90.032812

19. Ragonnet-Cronin M, Hué S, Hodcroft EB, Tostevin A, Dunn D, Fawcett T, et al. Non-disclosed men who have sex with men in UK HIV transmission networks: phylogenetic analysis of surveillance data. Lancet HIV. (2018) 5:e309-16. doi: 10.1016/S2352-3018(18)30062-6

20. Yan H, He W, Huang L, Wu H, Liang Y, Li Q, et al. The central role of nondisclosed men who have sex with men in human immunodeficiency virus1 transmission networks in Guangzhou, China. Open Forum Infect Dis. (2020) 7:ofaa154. doi: 10.1093/ofid/ofaa154

21. Zhong F, Lin $\mathrm{P}, \mathrm{Xu} \mathrm{H}$, Wang Y, Wang M, He Q, et al. Possible increase in HIV and syphilis prevalence among men who have sex with men in Guangzhou, China: results from a respondent-driven sampling survey. AIDS Behav. (2011) 15:1058-66. doi: 10.1007/s10461-009-9619-x

22. Das A, Li J, Zhong F, Ouyang L, Mahapatra T, Tang W, et al. Factors associated with HIV and syphilis co-infection among men who have sex with men in seven Chinese cities. Int J STD AIDS. (2015) 26:14555. doi: 10.1177/0956462414531560

23. Trifinopoulos J, Nguyen L-T, von Haeseler A, Minh B. W-IQ-TREE: a fast online phylogenetic tool for maximum likelihood analysis. Nucleic Acids Res. (2016) 44:gkw256. doi: 10.1093/nar/gkw256

24. Wertheim J, Kosakovsky Pond S, Forgione L, Mehta S, Murrell B, Shah S, et al. Social and genetic networks of HIV-1 transmission in New York City. PLoS Pathog. (2017) 13:e1006000. doi: 10.1371/journal.ppat.1006000

25. Ragonnet-Cronin M, Hodcroft E, Hué S, Fearnhill E, Delpech V, Brown AJ, et al. Automated analysis of phylogenetic clusters. BMC Bioinform. (2013) 14:317. doi: 10.1186/1471-2105-14-317

26. Rose R, Lamers SL, Dollar JJ, Grabowski MK, Hodcroft EB, RagonnetCronin $\mathrm{M}$, et al. Identifying Transmission Clusters with Cluster Picker and HIV-TRACE. AIDS Res Human Retroviruses. (2017) 33:211-8. doi: 10.1089/aid.2016.0205

27. Wang J, Mo H, Wang F, Jin F. Exploring the network structure and nodal centrality of China's air transport network: a complex network approach. J Transp Geogr. (2011) 19:712-21. doi: 10.1016/j.jtrangeo.2010.08.012

28. McGarry K, McDonald S. Complex network theory for the identification and assessment of candidate protein targets. Comput Biol Med. (2018) 97:11323. doi: 10.1016/j.compbiomed.2018.04.015 
29. De P, Singh AE, Wong T, Yacoub W, Jolly AM. Sexual network analysis of a gonorrhoea outbreak. Sex Transm Infect. (2004) 80:2805. doi: 10.1136/sti.2003.007187

30. Liu Y, Tang M, Zhou T, Younghae D. Core-like groups result in invalidation of identifying super-spreader by k-shell decomposition. Sci Rep. (2015) 5:9602. doi: 10.1038/srep09602

31. Kitsak M, Gallos L, Havlin S, Liljeros F, Muchnik L, Stanley H, et al. Identification of influential spreaders in complex networks. Nat Phys. (2010) 6:888-93. doi: $10.1038 /$ nphys 1746

32. Bader GD, Hogue CWV. An automated method for finding molecular complexes in large protein interaction networks. BMC Bioinformatics. (2003) 4:2. doi: 10.1186/1471-2105-4-2

33. Rosenbaum PR, Rubin DB. The central role of the propensity score in observational studies for causal effects. Biometrika. (1983) 70:4155. doi: 10.1093/biomet/70.1.41

34. Walsh MC, Trentham-Dietz A, Newcomb PA, Gangnon R, Palta M. Using propensity scores to reduce case-control selection bias. Epidemiology. (2012) 23:772-3. doi: 10.1097/EDE.0b013e3182628365

35. Wang C, Cheng W, Li C, Tang W, Ong JJ, Smith MK, et al. Syphilis Selftesting: a nationwide pragmatic study among men who have sex with men in China. Clin Infect Dis Offic Public Infect Dis Soc Am. (2020) 70:217886. doi: $10.1093 / \mathrm{cid} / \mathrm{ciz} 603$

36. Weiser J, Tie Y, Beer L, Pearson WS, Shouse RL. Receipt of prevention services and testing for sexually transmitted diseases among HIV-positive men who have sex with men, United States. Ann Internal Med. (2020) 173:162-4. doi: 10.7326/M19-4051

37. Zhang T, Liu C, Han L, Tang W, Mao J, Wong T, et al. Community engagement in sexual health and uptake of HIV testing and syphilis testing among MSM in China: a cross-sectional online survey. J Int AIDS Soc. (2017) 20:21372. doi: 10.7448/IAS.20.01/21372

38. Wang X, Wu Y, Mao L, Xia W, Zhang W, Dai L, et al. Targeting HIV prevention based on molecular epidemiology among deeply sampled subnetworks of men who have sex with men. Clin Infect Dis(2015) 61:14628. doi: $10.1093 / \mathrm{cid} / \mathrm{civ} 526$

39. Cao B, Saffer AJ, Yang C, Chen H, Peng K, Pan SW, et al. MSM behavior disclosure networks and HIV testing: an egocentric network analysis among MSM in China. AIDS Behav. (2019) 23:1368-74. doi: 10.1007/s10461-019-02404-z

40. Watts DJ, Strogatz SH. Collective dynamics of 'small-world' networks. Nature. (1998) 393:440-2. doi: 10.1038/30918
41. Achard S, Salvador R, Whitcher B, Suckling J, Bullmore E. A resilient, low-frequency, small-world human brain functional network with highly connected association cortical hubs. J Neurosci. (2006) 26:63-72. doi: 10.1523/JNEUROSCI.3874-05.2006

42. Xu T, Cullen KR, Mueller B, Schreiner MW, Lim KO, Schulz SC, et al. Network analysis of functional brain connectivity in borderline personality disorder using resting-state fMRI. Neuroimage Clin. (2016) 11:302-15. doi: 10.1016/j.nicl.2016.02.006

43. Muldoon SF, Bridgeford EW, Bassett DS. Small-world propensity and weighted brain networks. Sci Rep. (2016) 6:22057. doi: 10.1038/srep22057

44. CDC. The Center for Diseases Prevention and Control: prevalence and awareness of HIV infection among men who have sex with men -21 cities, United States, 2008. MMWR Morb Mortal Wkly Rep. (2010) 59:1201-7.

45. Denniston MM, Klevens RM, McQuillan GM, Jiles RB. Awareness of infection, knowledge of hepatitis $\mathrm{C}$, and medical follow-up among individuals testing positive for hepatitis C: National Health and Nutrition Examination Survey 2001-2008. Hepatology. (2012) 55:1652-61. doi: 10.1002/hep. 25556

46. Dowshen N, Binns HJ, Garofalo R. Experiences of HIV-related stigma among young men who have sex with men. AIDS Patient Care STDS. (2009) 23:3716. doi: 10.1089/apc.2008.0256

47. Kumar N, Forastiere L, Zhang T, Yang F, Li KT, Tang W, et al. Lack of sexual behavior disclosure may distort STI testing outcomes. BMC Public Health. (2020) 20:616. doi: 10.1186/s12889-020-08768-5

48. Stirrup OT, Copas AJ, Phillips AN, Gill MJ, Geskus RB, Touloumi G, et al. Predictors of CD4 cell recovery following initiation of antiretroviral therapy among HIV-1 positive patients with well-estimated dates of seroconversion. HIV Med. (2018) 19:184-94. doi: 10.1111/hiv.12567

Conflict of Interest: The authors declare that the research was conducted in the absence of any commercial or financial relationships that could be construed as a potential conflict of interest.

Copyright (c) 2021 Huang, Wu, Yan, Liang, Li, Shui, Han and Tang. This is an open-access article distributed under the terms of the Creative Commons Attribution License (CC BY). The use, distribution or reproduction in other forums is permitted, provided the original author(s) and the copyright owner(s) are credited and that the original publication in this journal is cited, in accordance with accepted academic practice. No use, distribution or reproduction is permitted which does not comply with these terms. 